\title{
Gastric evacuation for acute ethanol intoxication in a three year old
}

\author{
Sunny Zaheed Hussain, Jeewan Rawal, John A Henry
}

\begin{abstract}
A three year old girl presented in a deeply comatose state. She had drunk ethanol four hours previously and her blood ethanol concentration on arrival was 79.8 mmol/litre (3.69 g/litre). Because of her young age, high blood ethanol concentration, time since ingestion, and severe neurological depression on presentation, nasogastric aspiration of the stomach contents was performed and $4.2 \mathrm{~g}$ of ethanol were removed. She made an uneventful recovery.

(F Accid Emerg Med 1998;15:54-62)
\end{abstract}

Keywords: ethanol intoxication; child

Ethanol intoxication is not uncommon in children. Each year approximately 1000 children aged under 15 years are admitted to hospital in England and Wales suffering from acute ethanol intoxication. ${ }^{1}$ Although the incidence seems to be relatively high, only a few of these cases are serious. In a recent study ${ }^{1}$ of 143 children admitted to hospital with ethanol intoxication, only 17 were deeply unconscious, with a blood ethanol concentration greater than $43.4 \mathrm{mmol} /$ litre $(2 \mathrm{~g} /$ litre $)$ and needing intensive care. In the USA, death of a two year old female has been reported with an initial blood ethanol concentration of $2.68 \mathrm{~g} /$ litre, who showed poor ethanol clearance. ${ }^{2}$ Children under five are more prone to serious complications as they can rapidly drink large amounts of ethanol in relation to their body weight, thus quickly producing high blood ethanol concentrations. ${ }^{1}$ Children of this age group have a limited ability to metabolise an ethanol load since their hepatic ethanol dehydrogenase activity is not mature. ${ }^{3}$ Therefore life threatening ethanol poisoning is especially likely in this age group and the potential for hypoglycaemia and severe neurological depression is also high. ${ }^{4}$

\section{Case report}

A three year old child (weight $16.6 \mathrm{~kg}$ ) was brought to the accident and emergency (A\&E) department in an unconscious state with ethanol intoxication. According to her mother, she might have drunk as much as one quarter of a bottle of Malibu (7.5 units) and three quarters of a bottle of sparkling wine (1.5 units) at around $7.45 \mathrm{am}$. She became unconscious about 8.15 am, when an ambulance was called. The child was first taken to a nearby minor injury centre and finally arrived in the $A \& E$ department at $10.59 \mathrm{am}$.

On arrival in the resuscitation room she was unconscious, not responding to deep painful stimuli, and had a children's coma scale of $3 / 15$. Her breath smelt of ethanol. She was breathing spontaneously with a comfortable rate of $36 / \mathrm{min}$, and maintaining an oxygen saturation of $99 \%$ in air. Her heart rate was 120 beats $/ \mathrm{min}$, blood pressure was stable $(111 / 56 \mathrm{~mm} \mathrm{Hg}$ ), and she was well perfused. Her temperature was normal $\left(36.6^{\circ} \mathrm{C}\right)$. She was floppy and her reflexes were diminished. Pupils were of normal size, bilaterally equal and reacting, and she had no other focal neurological signs. There was no evidence of physical injuries or head trauma.

Management-Nasogastric aspiration was performed at 11.30 and yielded $220 \mathrm{ml}$ of pinkish coloured fluid. The initial blood alcohol concentration was very high at 79.8 $\mathrm{mmol} /$ litre ( $3.69 \mathrm{~g} /$ litre) (fig 1 ) four hours after the ethanol ingestion and $72 \mathrm{mmol} /$ litre $(3.3$ $\mathrm{g}$ /litre) six hours after ingestion. At this point an arterial blood gas analysis was performed to rule out metabolic acidosis. This showed $\mathrm{pH}$ $7.45, \mathrm{Po}_{2} 11.6 \mathrm{kPa}, \mathrm{PCO}_{2} 4.08 \mathrm{kPa}$, and base excess $-0.7 \mathrm{mmol} /$ litre. The child was managed in a general paediatric ward as a high dependency patient, as there was no bed available in the intensive therapy unit.

Serial blood ethanol and glucose levels were monitored and appropriate measures were taken to maintain normoglycaemia. The BMstix on admission gave a blood sugar value of $7.4 \mathrm{mmol} /$ litre and despite an infusion of $4 \%$ dextrose-saline the reading fell to $2.9 \mathrm{mmol} /$ litre after one hour, so the fluid regime was changed to $10 \%$ dextrose. The blood ethanol concentration declined rapidly and after about eight hours the child began to responding to pin prick. Spontaneous eye opening was noticed after 10 hours and she became fully oriented 13 hours after the ingestion (fig 1). Intravenous fluid was discontinued at this point. Overnight blood glucose concentrations were normal; ethanol concentrations were not measured overnight. The next morning, 26 hours after ingestion, the blood ethanol was $1.1 \mathrm{mmol} /$ litre 


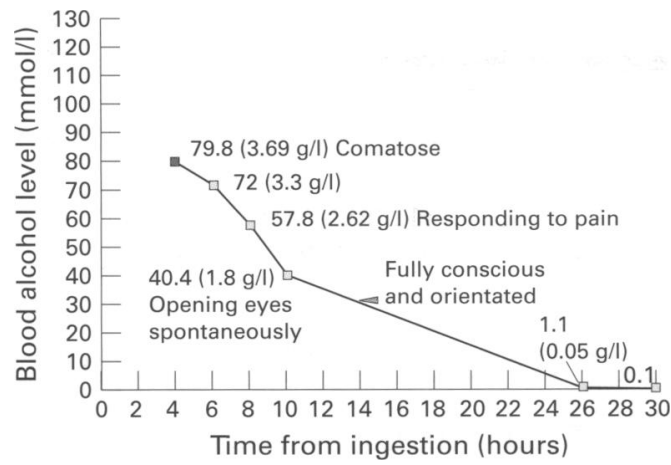

Figure 1 Serial blood alcohol concentrations after admission.

$(0.05 \mathrm{~g} /$ litre $)$ and before discharge a further sample showed a value less than $0.1 \mathrm{mmol} / \mathrm{litre}$. The child was discharged after 30 hours of hospital admission.

Meticulous care was taken to rule out any possible parental neglect or child abuse. The child belonged to a stable working class family and had two other siblings. The mother rang the general practitioner straight away, who reassured her rather inappropriately and this caused the delayed presentation to the hospital. There were no inconsistencies in the history. A thorough physical examination was normal, as was the skeletal survey. A drug screen revealed insignificant serum paraceta$\mathrm{mol}(0.02 \mathrm{mmol} / \mathrm{litre})$ and salicylate (0.02 $\mathrm{mmol} /$ litre), and no drugs of abuse were detected in the urine.

\section{Discussion}

Ethanol ingestion may cause varying degrees of central nervous system depression in children. The spectrum includes coma, hypotension, respiratory failure, and death. ${ }^{5}$ The breath usually has a characteristic odour and blood gas analysis often shows a mild metabolic acidosis. In this case, though the child was deeply comatose the blood gas analysis provided reassurance about her cardiorespiratory status.

Hypoglycaemia associated with ethanol ingestion in young children is more common than previously appreciated ${ }^{6-9}$ and can occur in up to $12 \%$ of children with ethanol overdose. ${ }^{5}$ It results mainly from inhibition of hepatic gluconeogenesis. ${ }^{10}$ Overnight fasting in children may potentiate this effect by reducing hepatic glycogen stores, so the toddlers who drink ethanol in the early morning are particularly vulnerable to hypoglycaemia. ${ }^{1}$ Intravenous dextrose should be the treatment of choice, since oral administration is unreliable and potentially dangerous. ${ }^{1}$ Clinical recognition of hypoglycaemia may be difficult, but delay in treatment may lead to convulsions, coma, permanent neurological damage, or death. $^{25811}$ In our case, careful monitoring of blood sugar was initiated from presentation and the blood sugar was adequately maintained.

The mean rate of clearance of ethanol from blood in adults is $20 \mathrm{mg} / \mathrm{dl} / \mathrm{h}$ but tends to be in the region of $30 \mathrm{mg} / \mathrm{dl} / \mathrm{h}$ in small children. ${ }^{12}$ The clearance rate can be calculated from the following formula ${ }^{13}$ : ethanol level No 1 - ethanol level No 2

time elapsed between levels in hours

In the present case, the rate of clearance was $31.5 \mathrm{mg} / \mathrm{dl} / \mathrm{h}$ during the first six hours of hospital admission and $16.6 \mathrm{mg} / \mathrm{dl} / \mathrm{h}$ overall. At high blood ethanol concentrations, ethanol metabolism by hepatic enzymes becomes saturated. ${ }^{5}$ In this situation excretion rather than metabolism plays the major role in ethanol clearance, following first order kinetics. ${ }^{2}$ However, because of the more rapid elimination which occurs in children, active elimination techniques are not usually necessary in young children with acute ethanol intoxication. $^{14}$

Gastric evacuation performed on a routine basis in adults does not usually affect the outcome in ethanol overdose $\mathrm{e}^{15}$ because it rarely retrieves significant quantities of ethanol..$^{5}$ Its role in children is not well described. In this case, the decision was made to aspirate by means of a narrow gauge tube without prior endotracheal intubation because this saved time in a patient whose condition was stable. It could be argued that the patient should have been intubated and ventilated to minimise the risk of aspiration, and this would have been the more acceptable practice. In the present case we aspirated $220 \mathrm{ml}$ of pinkish gastric content on arrival by nasogastric tube and a further 35 $\mathrm{ml}$ when the child was transferred to the ward. The ethanol content of the gastric aspirate was $4.2 \mathrm{~g}$ (in $255 \mathrm{ml}$ ). Although the aim of carrying out the procedure was to prevent further ethanol absorption and thus prevent possible deterioration, the actual amount recovered was only approximately $6 \%$ of the estimated ingested dose $(72 \mathrm{~g})$. Thus although the procedure might have only had a minor effect in this case, with an earlier presentation and earlier intervention it could have had a clinically significant effect.

\section{CONCLUSION}

Gastric decontamination is a difficult procedure to perform in children, but can be carried out with greater ease using a narrow gauge tube in cases of ethanol intoxication because of the liquid nature of the stomach contents. In the case presented, a not inconsiderable amount of ethanol was removed, even at four hours after ingestion. This procedure should be considered in acute ethanol intoxication in children, especially when the patient presents shortly after a large ingestion and is at risk of complications.

\footnotetext{
1 Beattie JO, Hull D, Cockburn F. Children intoxicated by ethanol in Nottingham and Glasgow, 1973-84. BMJ 1986;292:519-21.

2 Vogel C, Caraccio T, Mofenson H, Hart S. Ethanol intoxication in young children. Clin Toxicol 1995;33:25-33.

3 Hollstedt C, Olsson O, Rydberg U. The effect of ethanol on the developing organism. Med Biol 1977;55:1-14.

4 Lamminpaa A. Acute ethanol intoxication among children and adolescents. Eur J Pediatr 1994;153:868-72.

5 Proudfoot AT. Acute poisoning: diagnosis and management, 2nd ed. 1993.

6 Cornblath M, Schwartz R. Disorders of carbohydrate metabolism in infancy. Major problems in clinical paediatrics, vol 3. Philadelphia: WB Saunders, 1966:224-6.

7 Cummins LH. Hypoglycaemia and convulsions in children following ethanol ingestion. J Pediatr 1961;58:23-6.

8 Leung AKC. Ethyl ethanol ingestion in children: a 15 year review. Clin Pediatr 1986;12:617-9.
} 
9 Selbst SM, De Maio JG, Boenning D. Mouth wash poisoning. Clin Pediatr 1985;24:162-3.

10 Wright J. Ethanol-induced hypoglycaemia. Br J Alcohol Alcoholism 1979;14:174-6.

11 Ricci LR, Hoffman S. Ethanol induced hypoglycaemic coma in a child. Ann Emerg Med 1982;1 1:203-4.

12 Gershman H, Steeper J. Rate of clearance of ethanol from the blood of intoxicated patients in the emergency departthe blood of intoxicated patients in the
ment. J Emerg Med 1991;9:307-11.
13 Simon HK, Cox JM, Sucov A, Linakis JG. Ethanol clearance in intoxicated children and adolescents presenting to the ED. Acad Emerg Med 1994;1:520-4.

14 Gibson PJ, Cant AJ, Mant TGK. Ethanol poisoning. Acta Paediatr Scand 1985;74:977-8.

15 Pollack CV, Jorden RC, Carlton FB, Baker ML. Gastric emptying in the acutely inebriated patient. J Emerg Med emptying in the

See also letters on p00

\title{
CS gas exposure in a crowded night club: the consequences for an accident and emergency department
}

\author{
A Breakell, G G Bodiwala
}

\begin{abstract}
A case is reported of deliberate release of CS gas (O-chlorobenzylidene malononitrile) in an enclosed space and the consequences for an accident and emergency department.

(F Accid Emerg Med 1998;15:56-64)
\end{abstract}

Keywords: CS gas

\section{Case report}

Twenty three people (eight males, 15 females) attended the accident and emergency (A\&E) department at the Leicester Royal Infirmary following exposure to $\mathrm{CS}$ gas (O-chlorobenzylidene malononitrile) in a local night club. The average age of the males was 22 years and of the females, 21 . There were two known asthmatics in the group. The patients attended the A\&E department approximately $20 \mathrm{~min}$ utes after exposure to the CS gas and were in contact with the gas for 10 to 15 minutes while in the night club.

\section{TRIAGE}

On arrival at the $A \& E$ department, individuals were assessed at triage by an experienced nurse. Their clothes were removed and placed in plastic bags. Patients were triaged into two areas. The recovery ward of the A\&E department received those patients with minor symptoms and the windows were opened for ventilation. Patients with difficulty in breathing, chest tightness, and choking sensation also

Accident and

Emergency

Department, Leicester

Royal Infirmary,

Leicester, UK

A Breakell

G G Bodiwala

Correspondence to: Dr A Breakell, Accident and Emergency Department, Royal Liverpool University Hospital, Prescot Street, Liverpool L7 8XT, UK.

Accepted for publication 29 September 1997 had severe eye symptoms and were seen in the resuscitation room.

\section{CLINICAL ASSESSMENT}

Twelve of the 23 patients who attended the department discharged themselves before being seen by the doctor but had been assessed by a senior nurse on the recovery ward. Patients seen in the resuscitation room had eye and breathing problems. Irritation to the eyes was initially treated by blowing cold air from an electric fan onto the face. ${ }^{1}$ Six patients had eye irrigation with normal saline with considerable improvement in symptoms. Of those with respiratory problems, seven required supplemental oxygen. Two of these patients suffered from asthma. Clinically none of the patients developed wheeze but one asthmatic patient required a nebuliser for chest tightness. One patient was admitted to hospital with persistent chest tightness and sore throat. $\mathrm{He}$ was discharged after 24 hours with resolution of his chest tightness, but the sore throat persisted.

\section{Discussion}

While CS gas attacks are rare in this country at present, increasing availability of this substance at home and across Europe is likely to increase "the practical joke" and more serious cases of chemical terrorism and criminal attacks. The National Poisons Information Service (London) is currently attempting to monitor the number of incidents involving CS gas. ${ }^{2} \mathrm{At}$ present it is one of three agents used in crowd control, the others being 1-chloroacetophenone (CN gas) and dibenzoxazepine (CR gas). The use of $\mathrm{CN}$ and $\mathrm{CR}$ has decreased because of their toxic effects. Although called "gas," the chemicals are solids and are used in powder form. They are sprayed from liquid aerosols for convenience. The most toxic of these agents is CN gas which is a constituent of Mace, the self defence spray, and deaths from pulmonary injury and asphyxia have been reported; $\mathrm{CN}$ gas is also capable of causing serious damage to the eyes. ${ }^{3} \mathrm{CR}$ gas is the most potent lacrimator but has the least systemic effects. CS gas is a potent lacrimator and is the least toxic of the chemical compounds.

The effects of exposure to CS gas vary depending upon the concentration to which the person is exposed. On exposure even to low concentrations, the onset of symptoms is immediate. The effects usually settle within 15 to 30 minutes after removal from exposure. Eye, nose, mouth, respiratory tract, and skin symptoms predominate. ${ }^{4}$ Lacrimation, pain, blepharospasm, conjunctival erythema, and periorbital oedema develop, along with pain and discomfort in the nose, a burning sensation in the mouth, nausea and rarely vomiting, and respiratory symptoms of sore throat, tight chest, 